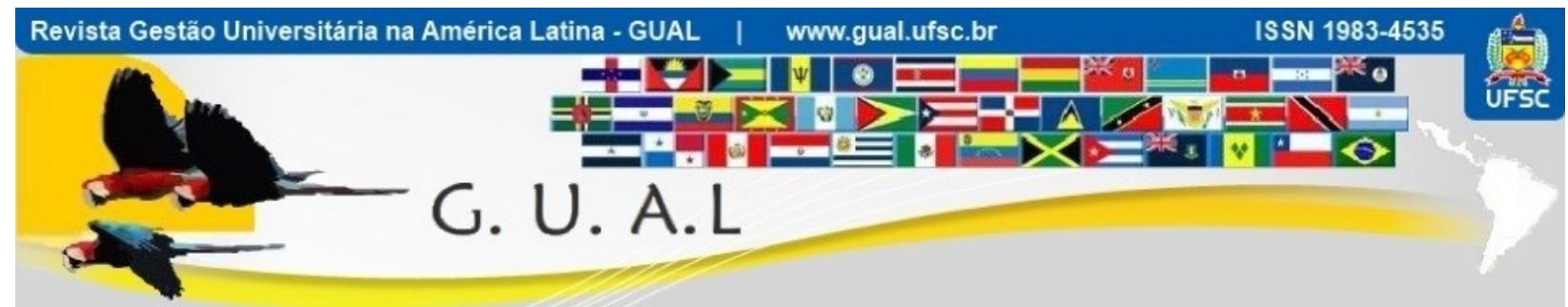

DOI: http://dx.doi.org/10.5007/1983-4535.2020v13n2p71

\title{
EFEITO DA BUROCRACIA NO CUSTO DE TRANSAÇÃO ECONÔMICA NA PRÓ-REITORIA DE ADMINISTRAÇÃO DA UNIVERSIDADE FEDERAL RURAL DO SEMI-ÁRIDO
}

\section{EFFECT OF BUREAUCRACY IN THE COST OF ECONOMICS TRANSACTION AT THE OFFICE OF THE VICE-PRESIDENT FOR ADMINISTRATION OF THE FEDERAL RURAL UNIVERSITY OF THE SEMI-ARID REGION}

Fabianny de Sales Guerra, Graduada https://orcid.org/0000-0002-5269-9453 nannysales@hotmail.com

Universidade Federal Rural do Semi-Árido | Curso de Ciências Contábeis Mossoró | Rio Grande do Norte | Brasil

Luciana Batista Sales, Doutora https://orcid.org/0000-0003-2748-6293 luciana@ufersa.edu.br

Universidade Federal Rural do Semi-Árido | Curso de Ciências Contábeis Mossoró | Rio Grande do Norte | Brasil

Carlos Alano Soares de Almeida, Doutor https://orcid.org/0000-0002-8350-2094 alano@ufersa.edu.br

Universidade Federal Rural do Semi-Árido | Curso de Ciências Contábeis Mossoró | Rio Grande do Norte | Brasil

Adriana Martins de Oliveira, Doutora https://orcid.org/0000-0001-5091-2671 adrimartinso@gmail.com Universidade do Estado do Rio Grande do Norte | Curso de Ciências Contábeis Mossoró | Rio Grande do Norte | Brasil

Antônio Erivando Xavier Júnior, Doutor https://orcid.org/0000-0001-7815-6257 erivando@ufersa.edu.br Universidade Federal Rural do Semi-Árido | Curso de Ciências Contábeis Mossoró | Rio Grande do Norte | Brasil

Recebido em 30/abril/2019

Aprovado em 04/fevereiro/2020

Publicado em 01/maio/2020

Sistema de Avaliação: Double Blind Review

Esta obra está sob uma Licença Creative Commons Atribuição-Uso. 


\title{
RESUMO
}

Esta pesquisa tem como objetivo identificar o efeito da burocracia no custo de transação econômica na Pró-Reitoria de Administração/PROAD da Universidade Federal Rural do Semi-Árido no Estado do Rio Grande do Norte. Nessa perspectiva, utilizou-se a abordagem qualitativa, que se desenvolveu por meio de um estudo de caso, mediante a triangulação dos dados coletados. Para tanto, inicialmente, foi posto em prática, o instrumento de coleta, por meio de uma entrevista semiestruturada com o Pró-Reitor da PROAD e a diretora do setor de contratos. Os dados foram tratados, atendendo aos preceitos da análise de conteúdo; para isso, primeiramente, transcreveu-se a entrevista, que posteriormente foi importada para o Software Atlas ti 8.0. Logo após, fez-se o trabalho de codificação que, com a finalização, empregou-se a categorização dos dados, com o propósito de criar famílias de acordo com as dimensões estudadas. Em seguida, foi possível conceber redes para a sua devida análise e discussões e por fim encontrar os resultados que respondessem ao problema de pesquisa. Os achados evidenciaram que a frequência das transações é nula, consequentemente, inexiste uma forte especificidade de ativos; bem como a racionalidade limitada, oportunismo e incerteza são atributos atenuados pelas normas burocráticas da Instituição.

Palavras-chave: Burocracia. Custo de Transação. Universidade.

\begin{abstract}
This research aims to identify the cost of economics transaction at the office of the vicepresident for administration/PROAD of the Federal Rural University of Semi-Arid Region in the state of Rio Grande do Norte. From this perspective, we used the qualitative approach, which was developed through a case study, through the triangulation of the data collected. To do so, initially, the collection instrument was put into practice, through a semi-structured interview with the Pro-Rector of PROAD and the director of the contract sector. The data were processed, taking into account the content analysis precepts; for this, the interview was transcribed first, which was later imported into Atlas ti 8.0 software. Afterwards, the coding work was done, which, with the conclusion, was used to categorize the data, with the purpose of creating families according to the dimensions studied. Then, it was possible to design networks for their due analysis and discussions and finally to find the results that answered the research problem. The findings showed that the frequency of transactions is zero, consequently, there is no strong asset specificity; as well as limited rationality, opportunism and uncertainty are attributes attenuated by the institution's bureaucratic norms.
\end{abstract}

Keywords: Bureaucracy. Transaction cost. University. 


\section{EFEITO DA BUROCRACIA NO CUSTO DE TRANSAÇÃO ECONÔMICA NA PRÓ-REITORIA DE ADMINISTRAÇÃO DA UNIVERSIDADE FEDERAL RURAL DO SEMI-ÁRIDO \\ DOI: http://dx.doi.org/10.5007/1983-4535.2020v13n2p71}

\section{INTRODUÇÃO}

O modelo burocrático ressalta aspectos formais, que irão controlar processos de decisão, ao estabelecer hierarquias baseadas em princípios de profissionalização e formalismo. O controle hierárquico ganha ênfase, na administração pública, dotado por funcionários especializados com competências fixas. "Há a profissionalização do funcionário burocrático, que exerce o cargo técnico em razão de sua competência, comprovada por processo de seleção" (SARTURI, 2013, p.1). É sabido que a administração pública trabalha, visando cumprir com os dispositivos legais que regulamentam as atividades, adotando a burocracia para fazer menção à forma de organização racional.

Conforme as transações existentes no setor público, diferentes custos de transação serão inferidos, o que poderia exigir uma diferente forma organizacional para governar essa transação. A teoria dos Custos de Transação Econômica busca estudar as relações existentes entre os diferentes agentes de determinado setor. Entre essas relações, irão existir fatores que interferem diretamente nas mesmas. O setor público, como o privado, busca economia nos custos da transação que realmente foram efetuadas. Assim, esta pesquisa tem como objetivo identificar o efeito da burocracia no custo de transação econômica na Pró-Reitoria de Administração (PROAD) da Universidade Federal Rural do Semi-Árido no Estado do Rio Grande do Norte. Para alcançar este objetivo, realizou-se uma pesquisa qualitativa, que teve como universo a Universidade Federal Rural do Semi-Árido, especificamente o setor de compras e contratos na Pró-reitoria de Administração da Universidade.

O ponto principal de análise é a transação, que se encontra estruturada por dois pilares: os pressupostos comportamentais e os atributos da transação. A transação representa a passagem de um bem ou serviço, em elaboração, entre partes tecnologicamente separáveis. No que diz respeito aos aspectos comportamentais dos agentes, são elencadas como importantes, para a compreensão da conduta, os pressupostos relacionados à racionalidade limitada e ao oportunismo (WILLIAMSON, 1981). Logo, procurar-se-á responder: qual é o efeito da burocracia no custo de transação econômica na Pró-Reitoria de Administração da Universidade Federal Rural do Semi-Árido no Estado do Rio Grande do Norte?

Segundo Motta (1979), a organização burocrática pode criar uma espécie de confiança, entre os funcionários, muito mais facilmente do que um mercado pode criar, entre as partes, em uma troca. As organizações burocráticas existem, pois, em determinadas condições, são o meio mais eficiente para uma mediação imparcial de transações entre os 


\section{EFEITO DA BUROCRACIA NO CUSTO DE TRANSAÇÃO ECONÔMICA NA PRÓ-REITORIA DE ADMINISTRAÇÃO DA UNIVERSIDADE FEDERAL RURAL DO SEMI-ÁRIDO \\ DOI: http://dx.doi.org/10.5007/1983-4535.2020v13n2p71}

agentes, para coordenar ações e interesses, entre indivíduos, e reduzir custos de transação. Williamson (1981) ressalta que, na comunicação estabelecida em uma negociação, as relações de confiança, tanto institucional como pessoal, podem evoluir; assim as pessoas que atuam nas interfaces transparecem a participação organizacional em uma transação.

Disseminar o efeito da burocracia sobre o custo de transação econômica, no setor público, justifica teoricamente esta pesquisa, em razão de proporcionar a percepção das relações existentes entre os agentes, do mesmo modo evidenciar os seus atributos: incerteza, frequência e especificidade de ativo e como os mesmos são afetados por um ambiente burocrático. Em termos práticos, foram identificados poucos estudos que venham a tratar da relação entre essas duas teorias. Logo, a sua contribuição é proporcionar, para a organização pública, a compreensão do que pode ser melhorado nas transações, assim como na minimização dos seus custos.

\section{REFERENCIAL TEÓRICO}

\subsection{BUROCRACIA}

De acordo com Marchetti, Carvalho e Mont'Alvão (2009), a burocracia é caracterizada como o modelo de gestão que se adapta melhor às necessidades da Administração pública, levando em consideração que a mesma busca diminuir os efeitos das interferências externas à organização, conciliando com a especialização dos seus participantes e o controle das suas atividades, atingindo os objetivos da organização de forma eficiente, sem levar em consideração aspectos pessoais. Os princípios da burocracia são os principais influenciadores para a caracterização de um modelo ideal de gestão, que são divididos em: impessoalidade nas relações; hierarquia da autoridade; rotinas e procedimentos padronizados; caráter legal e formal das normas; regulamentos das comunicações; caráter racional e divisão do trabalho.

Um dos princípios é remetido à impessoalidade das relações em razão da distribuição de atividades ser feita de acordo com os cargos e funções de determinada entidade. $\mathrm{O}$ princípio da hierarquia evidencia que existe uma ordem e subordinação que formará uma estrutura piramidal da burocracia. Para Santos e Bronneman (2013), a burocracia é necessária para as Instituições de Ensino Superior, uma vez que, por intermédio dela, existe o respeito à hierarquia para que os responsáveis por cada cargo estejam informados adequadamente. 


\section{EFEITO DA BUROCRACIA NO CUSTO DE TRANSAÇÃO ECONÔMICA NA PRÓ-REITORIA DE ADMINISTRAÇÃO DA UNIVERSIDADE FEDERAL RURAL DO SEMI-ÁRIDO \\ DOI: http://dx.doi.org/10.5007/1983-4535.2020v13n2p71}

Normas e regras são asseguradoras da disciplina no trabalho e do desempenho no cargo, o que leva o funcionário a cumprir as exigências da organização com o máximo de produtividade (MARCHETTI; CARVALHO; MONT’ALVÃO, 2009). Grin (2014), Oliveira (2015), Cosenza, Teixeira Filho e Lopes (2012) afirmam que o não cumprimento de ações legais implicam em sanções.

Tragtenberg (1989) trata burocracia como organização, poder e controle. Ele cita organização porque a burocracia precisa ser compartilhada e reproduzida para, assim, existir a própria civilização. Tratando-se de organização desde a sua forma propriamente dita, como se estrutura a divisão do trabalho, que origina uma subordinação na existência dos homens, até a burocracia existente no interior do Estado, onde é vista como processo de racionalização, que assegura a continuidade do processo civilizatório da modernidade.

Burocracia como poder, porque existem relações de dominação política e econômica. A superioridade técnica da burocracia moderna possibilita o estabelecimento do poder, dominando inclusive o homem em relação ao próprio homem. Mencionam burocracia como controle em razão da direta ligação com organizações produtivas e com o Estado. É por meio do Estado que se garante controle político-social diretamente à reprodução das demais organizações na sociedade. "A tecnologia que se emprega no interior da racionalidade burocrática, bem como as normas, as regras formais e os procedimentos são exemplos de meios instituídos de controle". (FARIA; MENEGHETTI, 2011, p. 437).

Max Weber, o pai da burocracia, enfrentou diversas críticas sobre suas pesquisas, por várias escolas de pensamento, nos mais variados campos de estudo, quando procurava mostrar que a burocracia não era absoluta e sofria uma série de disfunções (ARAGÃO, 1997). Segundo Girglioli (1995), a burocracia surgiu com uma profunda correlação negativa, pois havia uma vinculação de dependência do supremo com os demais funcionários do Estado francês, em uma concentração administrativa e absolutista. Para Aragão (1997), essa conotação negativa é vista também nos dias de hoje, não sendo esporádico o uso dos termos: abundância de papéis, normas rigorosas e excesso de formalismo. Reis e Cabral (2018) constataram, em seu estudo, que o excesso burocrático ocasiona redução no interesse dos municípios em aderir programas federais brasileiros.

Santos e Pereira (2012) asseguraram que os procedimentos rígidos e um alto grau de formalização restringem o mundo das ideias excelentes, inibindo a criatividade humana, fazendo com que as mudanças ocorram de forma lenta. Rosa e Frega (2017) constataram, em 


\section{EFEITO DA BUROCRACIA NO CUSTO DE TRANSAÇÃO ECONÔMICA NA PRÓ-REITORIA DE ADMINISTRAÇÃO DA UNIVERSIDADE FEDERAL RURAL DO SEMI-ÁRIDO \\ DOI: http://dx.doi.org/10.5007/1983-4535.2020v13n2p71}

sua pesquisa, que o excesso de procedimentos e autorizações, para realizar atividades no âmbito universitário, são barreiras existentes à interação universidade e empresa.

É por intermédio da burocracia que as organizações burocráticas buscam, cada vez mais, aumentarem a eficiência organizacional, ao utilizarem a racionalidade eficientemente, nos meios de produção, para alcançarem resultados econômicos. É, nas organizações, em que o indivíduo busca desenvolver-se, relacionar-se, ao fazer com que as organizações burocráticas impactem significativamente a sociedade, tanto em questão de desenvolvimento econômico, quanto social e político. (LYRIO; DELLAGNELO; LUNKES, 2017).

\subsection{TEORIA DO CUSTO DE TRANSAÇÃO (TCT)}

Coase (1937) afirma que há custos inerentes à organização e à discussão do contrato, quando utiliza o sistema de preços. Para ele, o objetivo final de um empreendedor é direcionar os recursos e economizar o possível com os custos de mercado, também conhecido como custos de transação econômica. Williamson (1985) ressalta que os custos de transação dizem respeito ao que é necessário, para que uma determinada entidade transacione bens e/ou serviços; além daqueles custos relacionados à sua produção; sendo os custos de transação vistos como um problema contratual.

Williamson (1985) aprofundou a teoria dos custos de transação, a partir da análise do comportamento humano e dos atributos de transação. Williamson (1981) afirma que o fundamental para a compreensão do comportamento está relacionado aos pressupostos comportamentais: racionalidade limitada e oportunismo, que são fatores determinantes nas relações econômicas. Com relação à racionalidade limitada, define-se que o ser humano tem limitações racionais e, com isso, não consegue aperfeiçoar as decisões tomadas, embora sejam satisfatórias. Esse fato se dá pela incapacidade de obter todas as informações prováveis de possibilidades e consequências das decisões.

Campos (2013, p.9) relaciona o oportunismo "à revelação incompleta ou distorcida de informações e, especialmente, aos esforços calculados de enganar, distorcer, desorientar, ofuscar ou de algum modo confundir". Segundo o autor, seria a assimetria informacional de forma intencional do indivíduo, satisfazendo seus próprios interesses, causando problemas econômicos para a organização. Dorneles et al. (2014) afirmam que a racionalidade limitada influência positivamente o comportamento oportunista, vistos que a racionalidade limitada cria contratos incompletos e por consequência, fonte para atitudes oportunistas. 


\section{EFEITO DA BUROCRACIA NO CUSTO DE TRANSAÇÃO ECONÔMICA NA PRÓ-REITORIA DE ADMINISTRAÇÃO DA UNIVERSIDADE FEDERAL RURAL DO SEMI-ÁRIDO \\ DOI: http://dx.doi.org/10.5007/1983-4535.2020v13n2p71}

Em se tratando dos atributos de transação, verificam-se três: especificidade de ativo, frequência e incerteza. Williamson (1985) explica que a especificidade de ativo diz respeito ao grau de reutilização que um ativo pode ter. Segundo ele as especificidades podem ser classificadas em: a) Especificidade de ativos humanos; b) Especificidade locacional ou geográfica; c) Especificidade de ativos dedicados; d) Especificidade física do ativo; e) Especificidade de marca; f) Especificidade temporal.

Conforme Williamson (1985), quanto maior for a especificidade de ativos de uma transação, maiores serão os custos envolvidos. Para o autor, a especificidade de ativo exalta a dependência bilateral entre as partes; contudo, a baixa especificidade reduz a dependência entre os agentes. Mello e Paulillo (2009) e Martins e Souza (2014) afirmam que a especificidade de ativos envolvida nos produtos, a elevada incerteza e a forte assimetria de informações presentes nessas transações implicam na necessidade de contratos bem desenhados para a comercialização, para que problemas derivados do oportunismo e da racionalidade limitada dos agentes não ocorram.

Para Williamson (1985), a incerteza se relaciona com a dificuldade de identificar informações por parte dos indivíduos envolvidos na transação, bem como à insegurança proporcionada pelo ambiente em razão da continuidade das decisões acordadas. Para ele, a incerteza teria seu fim, se a racionalidade limitada não existisse, pois os agentes poderiam organizar estratégias minuciosas com o intuito de evitar os fatos possíveis.

A frequência é um importante fator a ser considerado, sendo definido pela quantidade de vezes que a transação passa a ocorrer. A reputação construída, entre os agentes, passa a ser maior no momento em que a frequência das transações é recorrente. Assim, quanto maior a frequência, menor poderá ser os custos associados a ela, em várias transações (WILLIAMSON, 1985). Santos e Padula (2012) e Dorneles et al. (2014), constataram, em sua pesquisa, que a frequência nas transações aumenta a confiança entre os agentes e a lealdade das partes, fazendo ligação direta com a redução do oportunismo e da incerteza.

\section{PROCEDIMENTO METODOLÓGICO}

Esta pesquisa tem como objetivo identificar o efeito da burocracia no custo de transação econômica na Pró-Reitoria de Administração/PROAD da Universidade Federal Rural do Semi-Árido no Estado do Rio Grande do Norte. Nessa perspectiva, utilizou-se a abordagem qualitativa que foi desenvolvida por meio de um estudo de caso, mediante a 


\section{EFEITO DA BUROCRACIA NO CUSTO DE TRANSAÇÃO ECONÔMICA NA PRÓ-REITORIA DE ADMINISTRAÇÃO DA UNIVERSIDADE FEDERAL RURAL DO SEMI-ÁRIDO \\ DOI: http://dx.doi.org/10.5007/1983-4535.2020v13n2p71}

triangulação dos dados, que ocorreu por meio de entrevista, observação e análise documental. A pesquisa teve um caráter descritivo e exploratório construído a partir de entrevista semiestruturada, que ocorreu em dois momentos: no primeiro, entrevistou-se o Pró-Reitor de Administração; no segundo, conversou-se com a diretora de contratos.

Apesar de ter havido dois momentos para a captação dos dados, o recorte temporal, para a realização do estudo, correspondeu ao transversal, porque a entrevista ocorreu em um determinado ponto no tempo. A entrevista foi dividida em quatro blocos: o primeiro para identificação do perfil do entrevistado; o segundo fez referência aos custos de transação econômica do setor; o terceiro tratou da burocracia existente nas transações; e o quarto relacionou a burocracia com os custos de transação econômica.

As entrevistas foram gravadas em áudio, e, posteriormente, transcritas, a fim de obter com precisão todos os dados primários, que seriam necessários para responder o problema de pesquisa. As informações foram tratados por meio de análise de conteúdo. Logo após, os dados foram importados para o software ATLAS TI 8.0, para serem sistematizados. Assim, selecionou-se a unidade de analise que correspondeu a um tema, para lhe ser atribuído um código, que foi direcionado ao administrador de códigos do sistema. Em seguida, foi categorizado com o propósito de criar redes de acordo com as dimensões estudadas: burocracia, racionalidade limitada, oportunismo, especificidade de ativo, incerteza e frequência; as quais foram analisadas e discutidas.

\section{RESULTADOS E DISCUSSÕES}

\subsection{BUROCRACIA}

Com o intuito de atingir o objetivo geral da pesquisa, identificaram-se, inicialmente, os trâmites necessários para o processo de aquisição de bens e serviços. Verificou-se que, para este fim, segue-se o que está fundamentado na lei 8.666 de 21 de junho de 1993, a qual institui normas para licitações e contratos da Administração Pública, bem como algumas instruções normativas (BRASIL, 1993).

A centralização administrativa, como forma de burocracia, é a maneira em que os responsáveis, por cada nível hierárquico, estejam informados para agir eficazmente (SANTOS; BRONNEMANN, 2013).

Em conformidade com a pesquisa de Rosa e Frega (2017), que aborda os intervenientes do processo de transferência tecnológica em uma Universidade Pública, 


\section{EFEITO DA BUROCRACIA NO CUSTO DE TRANSAÇÃO ECONÔMICA NA PRÓ-REITORIA DE ADMINISTRAÇÃO DA UNIVERSIDADE FEDERAL RURAL DO SEMI-ÁRIDO \\ DOI: http://dx.doi.org/10.5007/1983-4535.2020v13n2p71}

constatou-se que existe uma barreira entre a relação universidade e empresas fornecedoras, a qual é proveniente da burocracia excessiva da universidade pública brasileira, o que corrobora com esta pesquisa, conforme Figura 1.

Figura 1 Rede Burocracia

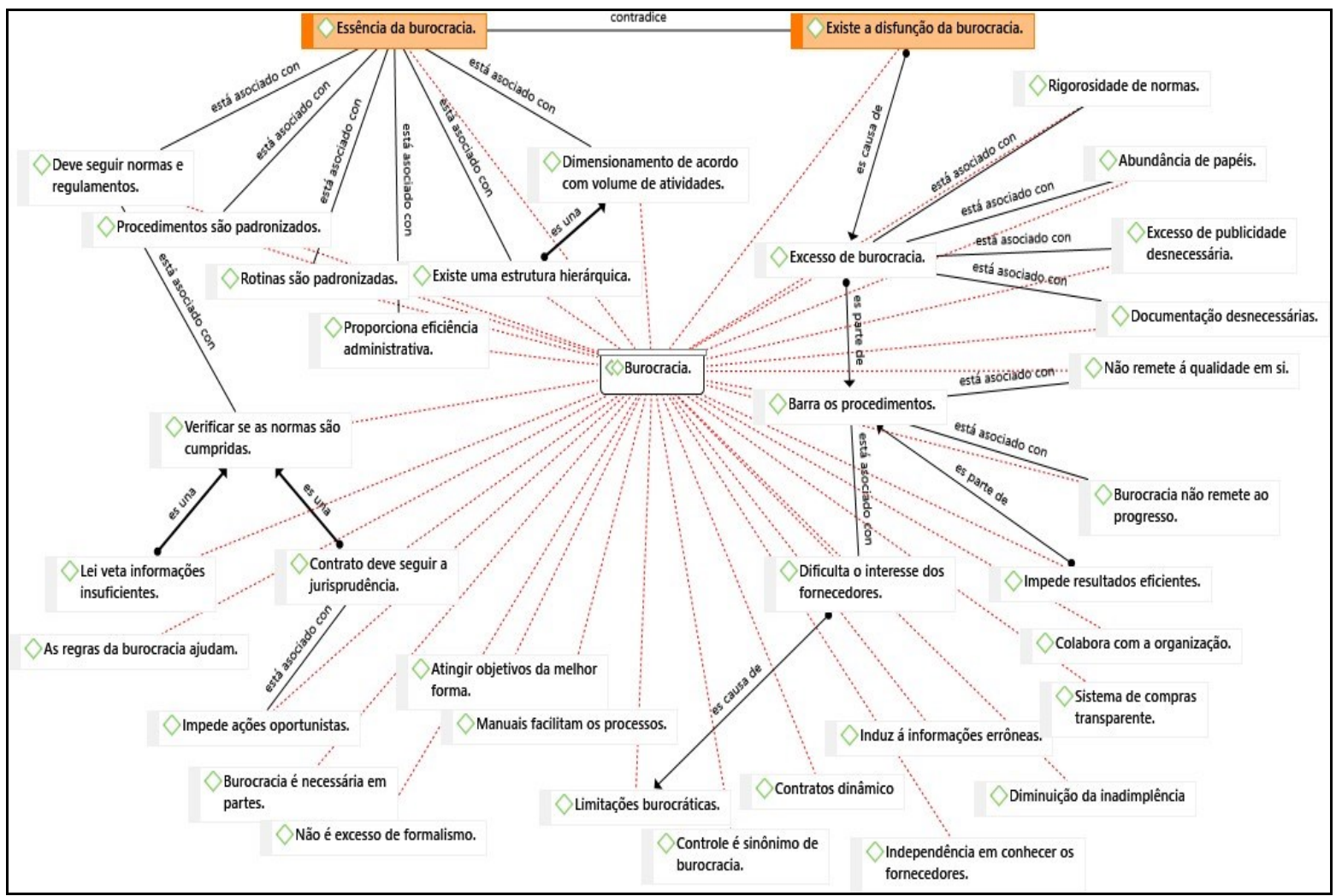

Fonte: elaborada pelos autores (2018).

Na pesquisa, identificou-se a burocracia, na sua essência, bem como a disfunção da burocracia, conforme Figura 1. A burocracia defendida por Weber (1982) evidencia as rotinas e os procedimentos de maneira padronizada, devendo seguir normas e regulamentos. Neste estudo, foi visto que para cada procedimento adotado na instituição, existem os manuais que norteiam as operações, os quais facilitam o processo em si. Oliveira (2015), em seu estudo sobre eficiência e eficácia no processo de compras públicas, afirma que o constructo eficiência está intimamente ligado com os trâmites processuais e meios para se obter resultados.

O que excede a burocracia, conhecido como disfunção, acarreta em rigorosidade de normas, abundância de papeis, bem como a desqualificação dos processos. O entrevistado afirma que certas documentações exigidas em normas, são escusáveis, ocasionando atrasos 


\section{EFEITO DA BUROCRACIA NO CUSTO DE TRANSAÇÃO ECONÔMICA NA PRÓ-REITORIA DE ADMINISTRAÇÃO DA UNIVERSIDADE FEDERAL RURAL DO SEMI-ÁRIDO \\ DOI: http://dx.doi.org/10.5007/1983-4535.2020v13n2p71}

nos processos e impedindo resultados eficientes, corroborando com os estudos de Santos e Pereira (2012).

O modelo burocrático que influencia as licitações bem como o gerenciamento da administração pública brasileira é fundamentado na racionalidade. A garantia da eficiência administrativa e o controle público das ações estão embasados nessa racionalidade, que consequentemente conduz à profissionalização e impessoalidade dos funcionários (OLIVEIRA, 2015). Segundo Santos e Marques (2015), as organizações burocráticas, em algumas ocasiões, são mais eficientes para estruturar ações e dizimar custos de transação.

\subsection{RACIONALIDADE LIMITADA}

Para Klein, Pizzio e Rodrigues (2017), uma das formas de reduzir a racionalidade limitada corresponde à maneira em que a instituição se prepara para as suas negociações. Outras alternativas de preparo, para as negociações, como forma de reduzir a racionalidade limitada existente, são estudos realizados anteriormente, seja por meio eletrônico, universidades e, até mesmo, pelo próprio demandante do bem ou serviço.

Logo, identificou-se, nesta pesquisa, que durante a execução dos contratos, surgiam informações que não foram percebidas inicialmente. Segundo o entrevistado, essas lacunas são decorrentes de vários fatores: mudança na carga tributária, reequilíbrio econômico e financeiro, bem como o custo da matéria-prima, em consonância com a Figura 2.

De acordo com a Figura 2, percebe-se a necessidade de conhecimentos técnicos para as negociações. Contudo, é necessário estudo, planejamentos, busca de informações e até mesmo investimentos em capacitação dos servidores, a fim de evitar o surgimento de lacunas indesejáveis no ciclo contratual, como observado nos estudos de Lopes (2017).

Logo, percebe-se que a sistematização do processo de compra, regido por leis, normas e manuais, favorece a redução da racionalidade limitada, em razão de reunir somente informações eficientes para execução das atividades na administração pública.

No entanto, a racionalidade limitada não é reduzida na sua plenitude, em razão do ser humano não ter a capacidade de conhecer integralmente tudo que está a sua volta. $\mathrm{Na}$ administração pública, não seria diferente, pois apesar de existir critérios que restrinjam resultados indesejados, pôde-se identificar, nesta pesquisa, descumprimento por parte do fornecedor do que foi pré-estabelecido no contrato, conforme também os estudos de Martins e Souza (2014). 


\section{EFEITO DA BUROCRACIA NO CUSTO DE TRANSAÇÃO ECONÔMICA NA PRÓ-REITORIA DE ADMINISTRAÇÃO DA UNIVERSIDADE FEDERAL RURAL DO SEMI-ÁRIDO \\ DOI: http://dx.doi.org/10.5007/1983-4535.2020v13n2p71}

Figura 2 Rede Racionalidade Limitada

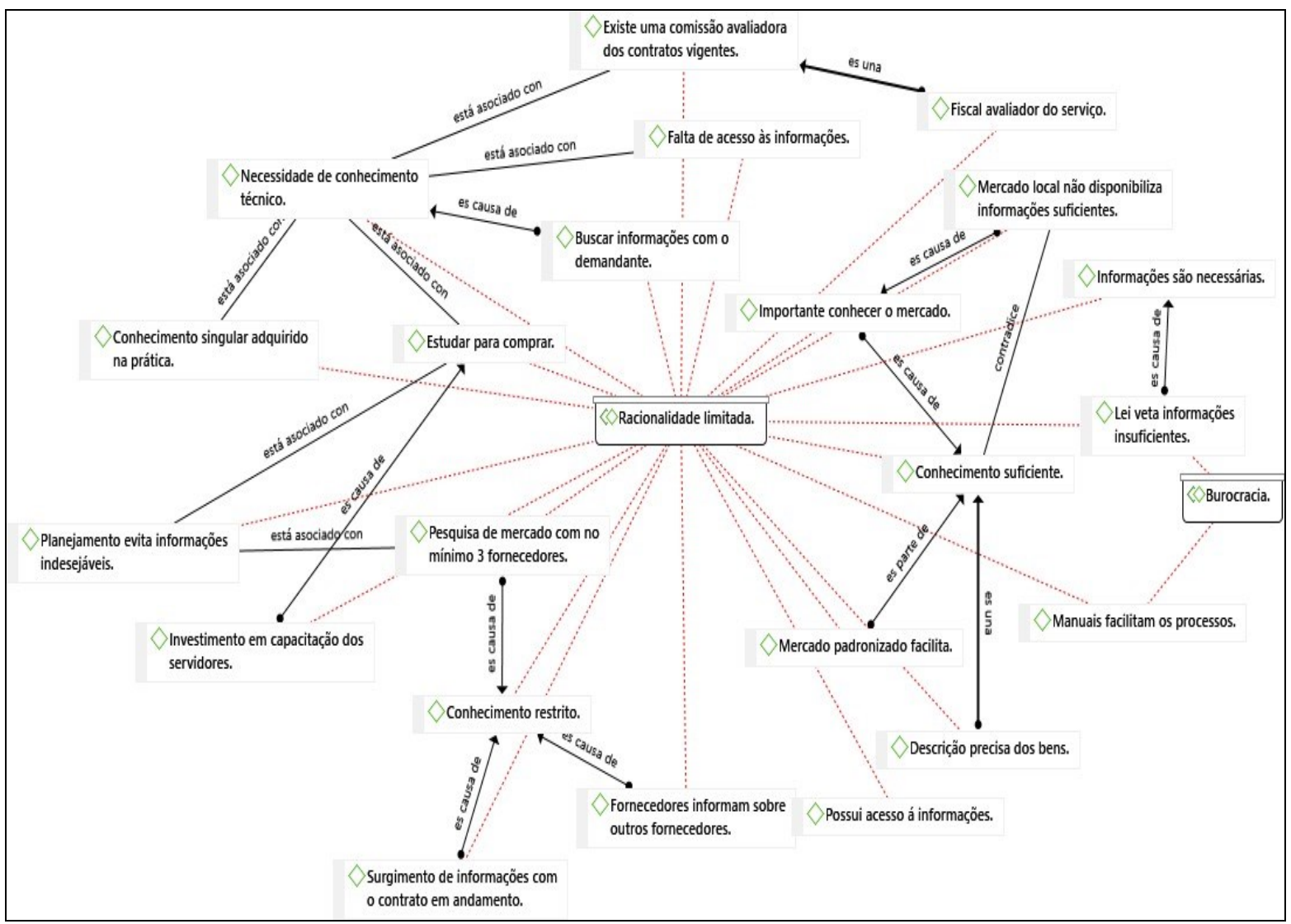

Fonte: elaborada pelos autores (2018).

\subsection{OPORTUNISMO}

De acordo com a pesquisa, verificou-se que as rescisões contratuais são realizadas em casos extremos. Para a entrevistada, o descumprimento contratual acontece com mais frequência nos contratos de terceirização, em virtude da inadimplência das empresas devido às obrigações trabalhistas. Mesmo após as notificações, caso continuem as transgressões, serão aplicadas sanções que estão previstas nos contratos.

A pesquisa apontou que a inexecução total ou parcial do contrato poderá acarretar em algumas sanções decorrentes do que foi pré-estabelecido no acordo contratual entre as partes. As sanções variam entre advertência verbal, multa, suspensão temporária de licitar e impedimento de se relacionar com a administração por prazo não superior a dois anos; bem como, em casos extremos, a emissão de declaração de inidoneidade para licitar, que valerá até quando permanecer as razões da punição.

Segundo Cosenza, Teixeira Filho e Lopes (2012), em seus estudos sobre poder e contabilidade, declaram que, no campo contábil, são utilizadas sanções punitivas a fim de 


\section{EFEITO DA BUROCRACIA NO CUSTO DE TRANSAÇÃO ECONÔMICA NA PRÓ-REITORIA DE ADMINISTRAÇÃO DA UNIVERSIDADE FEDERAL RURAL DO SEMI-ÁRIDO \\ DOI: http://dx.doi.org/10.5007/1983-4535.2020v13n2p71}

autuar irregularidades no cumprimento obrigatório das normas.

Os códigos, que configuram o oportunismo, nesta pesquisa, foram relacionados no Atlas ti 8.0, e deram origem à seguinte rede, de acordo com a Figura 3.

Figura 3 Rede Oportunismo

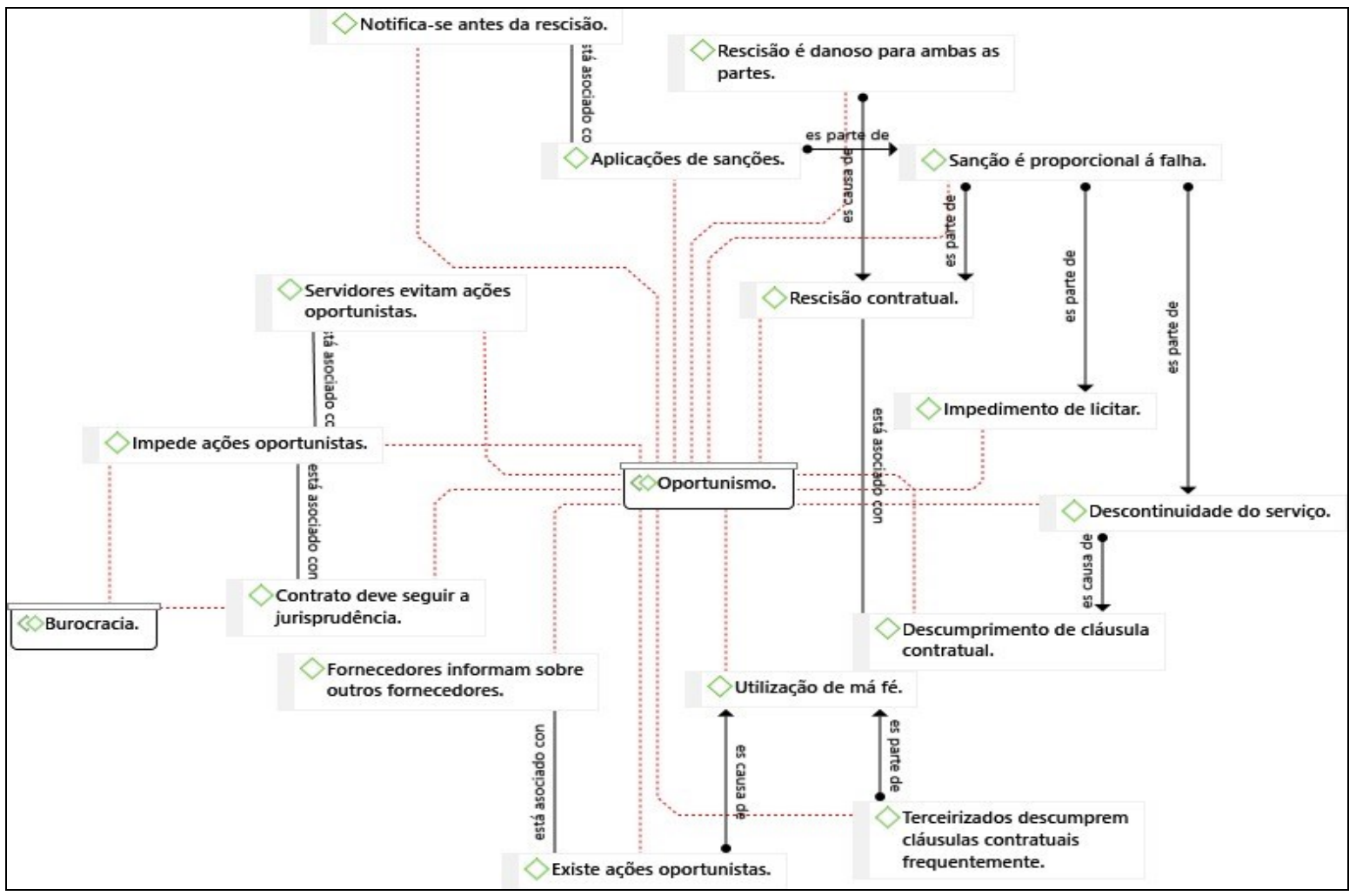

Fonte: Elaborada pelos autores (2018)

Na Figura 3, pôde-se perceber, no processo de contratação, que não é necessário conhecer literalmente os fornecedores, já que a escolha dos mesmos é feita com base no menor preço. Segundo Cario, Neuenfeld e Stadnick (2017), em seus estudos, viu-se que a relação independente das partes relacionadas, em união com interesses conflitantes, aumenta a possibilidade do comportamento oportunista.

De acordo com Oura et al. (2012), em sua pesquisa sobre controle de oportunismo no Pregão Eletrônico, foi constatado que embora o sistema eletrônico aumente a eficiência das operações, bem como o cumprimento da legislação pertinente, o mesmo parece não ser eficaz para moderar ações oportunistas, tendo em vista que, para este fato, seriam necessários recursos tecnológicos que viabilizassem um sistema de inteligência e aprendizado organizacional. 


\section{EFEITO DA BUROCRACIA NO CUSTO DE TRANSAÇÃO ECONÔMICA NA PRÓ-REITORIA DE ADMINISTRAÇÃO DA UNIVERSIDADE FEDERAL RURAL DO SEMI-ÁRIDO \\ DOI: http://dx.doi.org/10.5007/1983-4535.2020v13n2p71}

Observou-se, neste estudo, que em razão da aplicação de sanções e rescisões contratuais mediante ao não cumprimento dos contratos, as ações oportunistas são minimizadas, corroborando com a pesquisa de Bairral, Silva, e Alves (2014).

Os custos de transação possuem relação direta no que concerne à eficiência nas compras públicas. As transações como: planejamento de compras, negociações, controle de entrega dos materiais e gestão contratual, incorrem custos envolvido com itens presentes nas mesmas. Essas transações abrangem comportamentos dos elementos envolvidos, como a racionalidade limitada e o oportunismo, bem como variáveis inerentes à transação, chamadas de especificidade do ativo, frequência e incerteza.

\subsection{ESPECIFICIDADE DE ATIVOS}

Identificou-se, nesta pesquisa, que para aquisição de alguns itens, pode-se considerar a localização geográfica como um ativo específico; porém, para outros bens, como equipamentos, a localização geográfica não favorece, pois esses itens são adquiridos fora da região.

Em se tratando de atributos específicos do capital humano, como habilidades e competências, o entrevistado declara que os servidores são capacitados periodicamente e exerce a sua função com competência. Enfatiza também que a experiência vivida, no dia a dia, dos servidores é tão importante quanto a capacitação que a instituição oferece. A entrevistada ressalta que os contratos de bens e/ou serviços são complexos, apresentando características singulares, que só serão assimilados com a prática.

Oura et al. (2012), ressaltam que existem licitações altamente competitivas, como exemplo: matérias de informática e de expediente, bem como licitações, em que poderá participar um único fornecedor, ou nenhum. Essa situação irá depender de alguns fatores como: a especificidade do objeto, o valor que será estimado para contratação, exigências do edital e entre outros fatores que irão definir a atratividade do licitante para atender as exigências da entidade, conforme Figura 4.

$\mathrm{O}$ entrevistado apontou que as aquisições de gases específicos, para laboratórios e contratação de serviços de manutenção, devem ser utilizadas para um único e exclusivo fim. Em se tratando de especificidade de localização, o estudo identificou que alguns itens específicos demandados não existem no mercado local, dificultando as aquisições e 


\section{EFEITO DA BUROCRACIA NO CUSTO DE TRANSAÇÃO ECONÔMICA NA PRÓ-REITORIA DE ADMINISTRAÇÃO DA UNIVERSIDADE FEDERAL RURAL DO SEMI-ÁRIDO \\ DOI: http://dx.doi.org/10.5007/1983-4535.2020v13n2p71}

incorrendo em maiores custos de transação. Por outro lado, há produtos que possuem uma característica peculiar, porém de fácil acesso no mercado local.

Figura 4 Rede Especificidade de Ativos

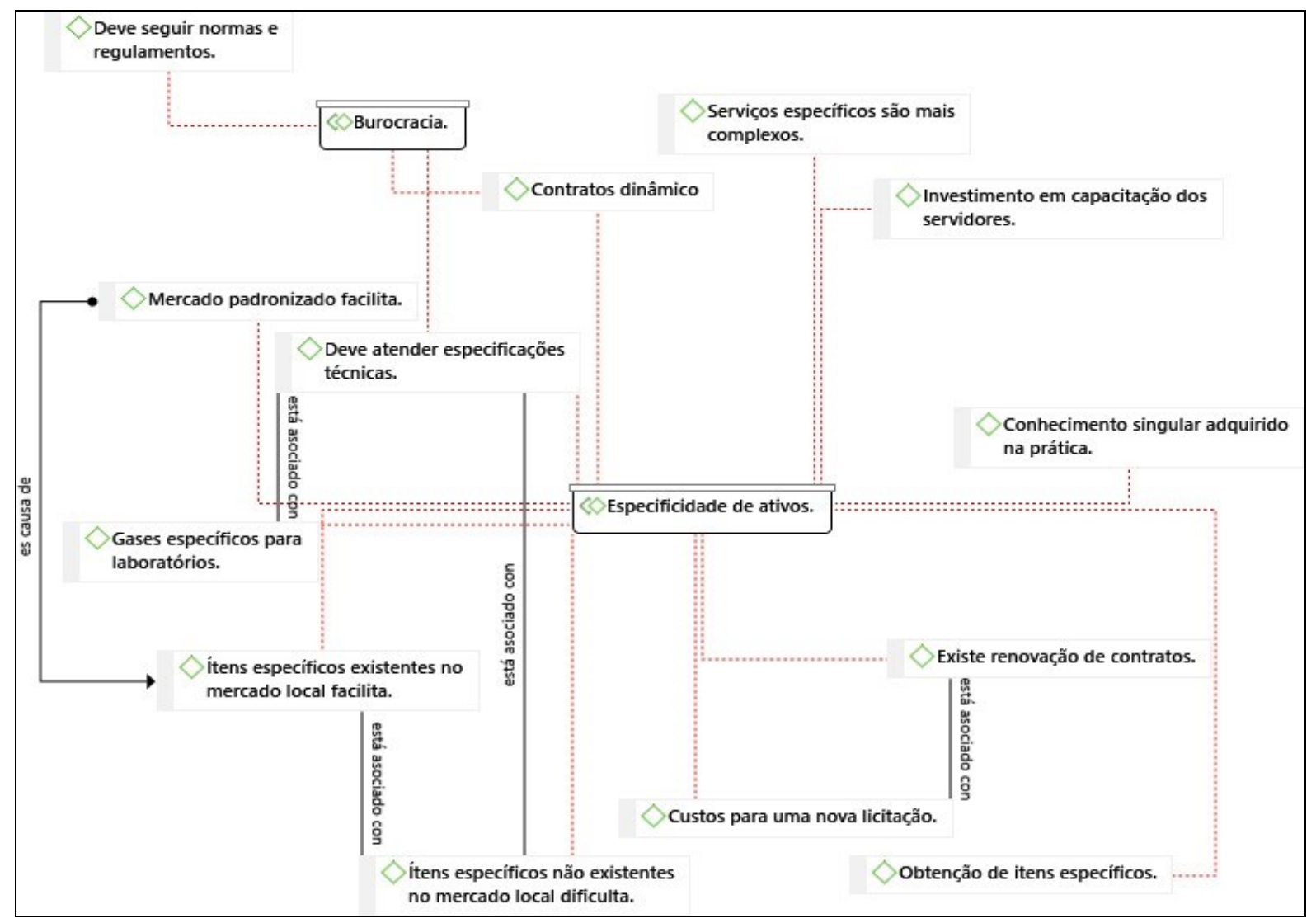

Fonte: elaborada pelos autores (2018).

A especificidade do ativo humano se relaciona com o aprendizado adquirido pelos usuários ao realizarem determinadas atividades (CARVALHO JR.; OZON, 2004). Nesta pesquisa, observou-se que os servidores alcançam bastante conhecimento, provenientes das experiências com as atividades exercidas no dia a dia de trabalho, bem como ocorre também investimento em capacitação dos servidores sendo periodicamente realizado.

Em se tratando das especificidades de ativos não identificados, pôde-se observarque a especificidade temporal e de ativo dedicado, não existem. A especificidade de marca está associada com a importância específica da mesma para a atividade. Percebe-se que a lei 8.666/93, a qual rege as compras públicas, especifica que é vedado a realização de licitações, incluindo bens e serviços com a presença de marcas, ou presença de similares. 


\section{EFEITO DA BUROCRACIA NO CUSTO DE TRANSAÇÃO ECONÔMICA NA PRÓ-REITORIA DE ADMINISTRAÇÃO DA UNIVERSIDADE FEDERAL RURAL DO SEMI-ÁRIDO \\ DOI: http://dx.doi.org/10.5007/1983-4535.2020v13n2p71}

\subsection{INCERTEZA}

No que diz respeito às transações entre fornecedor e instituição, a entrevistada afirma existir, em alguns casos, uma relação difícil, em razão da dificuldade do mesmo obedecer ao que foi estabelecido no contrato. Porém, como as relações são realizadas mediante arranjos contratuais, o descumprimento de qualquer cláusula, ocasionará aplicação de sanções.

Reis e Cabral (2018) evidenciaram, em sua pesquisa, que apesar da contratação dos serviços ocorrerem mediante licitações eletrônicas altamente padronizadas, não descarta a possibilidade do surgimento das incertezas, que podem não ser observadas nas compras. No estudo, o entrevistado afirma que o planejamento de compras é realizado com o objetivo de evitar incertezas.

Em se tratando das transações entre fornecedor e instituição, a entrevistada afirma existir, em alguns casos, uma relação difícil, devido à dificuldade do mesmo obedecer ao que foi estabelecido no contrato. Porém, como as relações são realizadas mediante arranjos contratuais, o descumprimento de qualquer cláusula, ocasionará aplicação de sanções. A rede incerteza está representada na Figura 5.

O entrevistado elucida a impossibilidade de criar cláusulas contratuais que possam prever a realidade futura do mercado. Identificou-se a carga tributária como sendo um fator que interfere no valor do contrato no decorrer da sua execução, em razão das mudanças frequentes na legislação brasileira.

Segundo dados da pesquisa, o planejamento de compras, realizado antecipadamente ao contrato, evita informações indesejáveis. Cario, Neuenfeld e Stadnick (2017), em sua pesquisa, afirmam que apesar da impossibilidade de descartar em sua plenitude a incerteza existente, nas transações, a estabilidade das organizações públicas reduz tais impactos negativos, uma vez que os contratos padronizados com salvaguardas controlam os custos de transação.

Já nos estudos de Dorneles et al. (2014), pode-se concluir que o nível de incerteza existente entre os agentes é baixo, em razão das relações serem sólidas, baseadas na confiança entre agentes. Santos e Padula (2012) afirmam, em seu estudo, que um dos pontos para a redução da incerteza é a frequência na qual ocorre a transação. 
Figura 5 Rede Incerteza

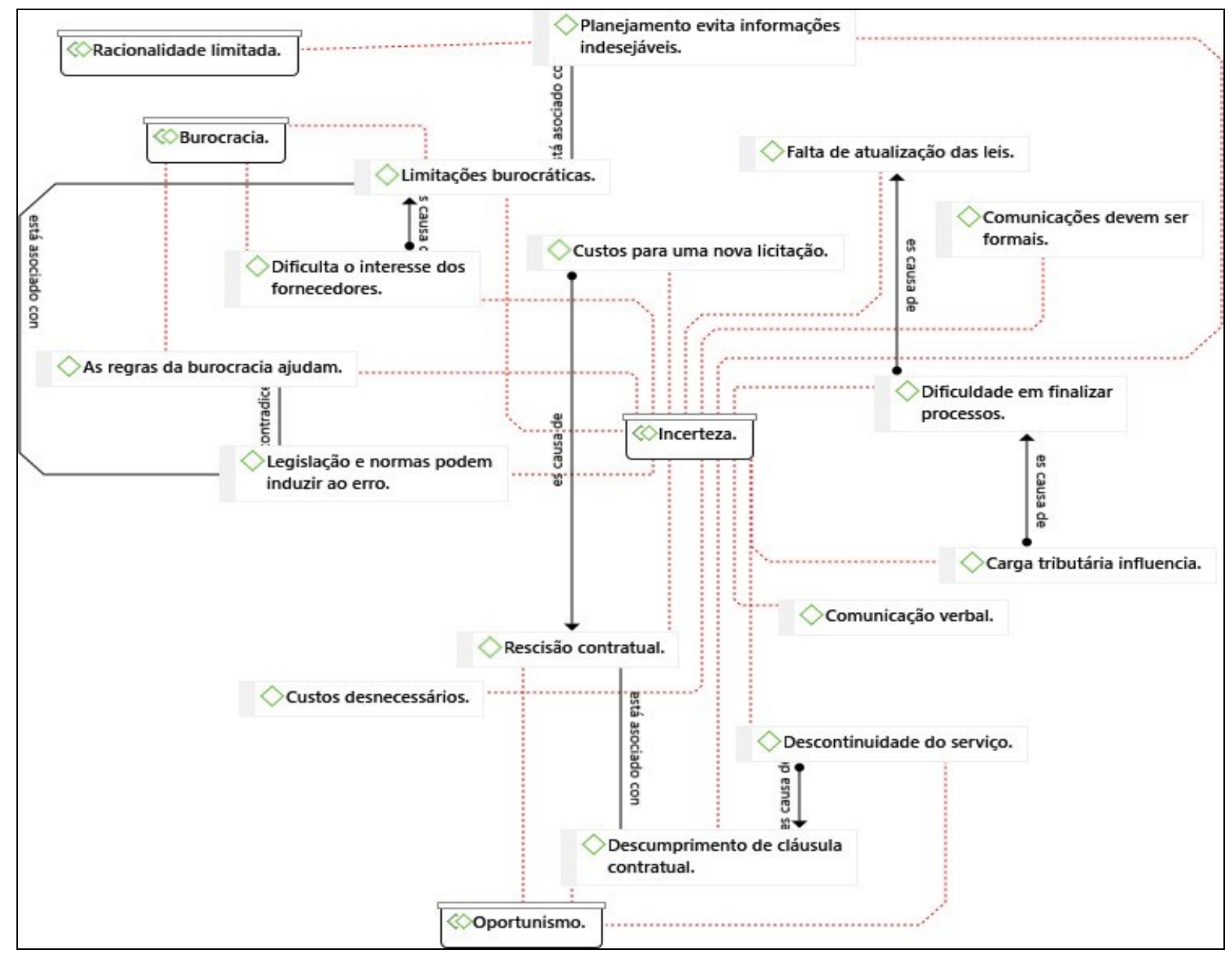

Fonte: elaborada pelos autores (2018).

\subsection{FREQUÊNCIA}

De acordo com o entrevistado, as transações são realizadas por meio de licitações, as quais nortearão a escolha com base no menor preço, ou seja, ganhará aquele que apresentar o melhor valor dentro das especificações técnicas. Logo, identificou-se que a frequência inexiste nesta relação, isto é, as partes não criam uma dependência bilateral, como pode ser visto na Figura 6.

Cario, Neuenfeld e Stadnick (2017) observaram que a baixa frequência transacional com os fornecedores, aumentou os custos de transação, devido não existir um ambiente de confiança entre as partes. De forma similar, identificou-se, nesta pesquisa, que as transações não são frequentes; contudo, este fato acontece em virtude da peculiaridade do setor público, o qual trabalha suas aquisições com base em normas e regulamentos, para selecionar o seu fornecedor, mediante o menor preço ofertado. 


\section{EFEITO DA BUROCRACIA NO CUSTO DE TRANSAÇÃO ECONÔMICA NA PRÓ-REITORIA DE ADMINISTRAÇÃO DA UNIVERSIDADE FEDERAL RURAL DO SEMI-ÁRIDO \\ DOI: http://dx.doi.org/10.5007/1983-4535.2020v13n2p71}

Figura 6 Rede Frequência

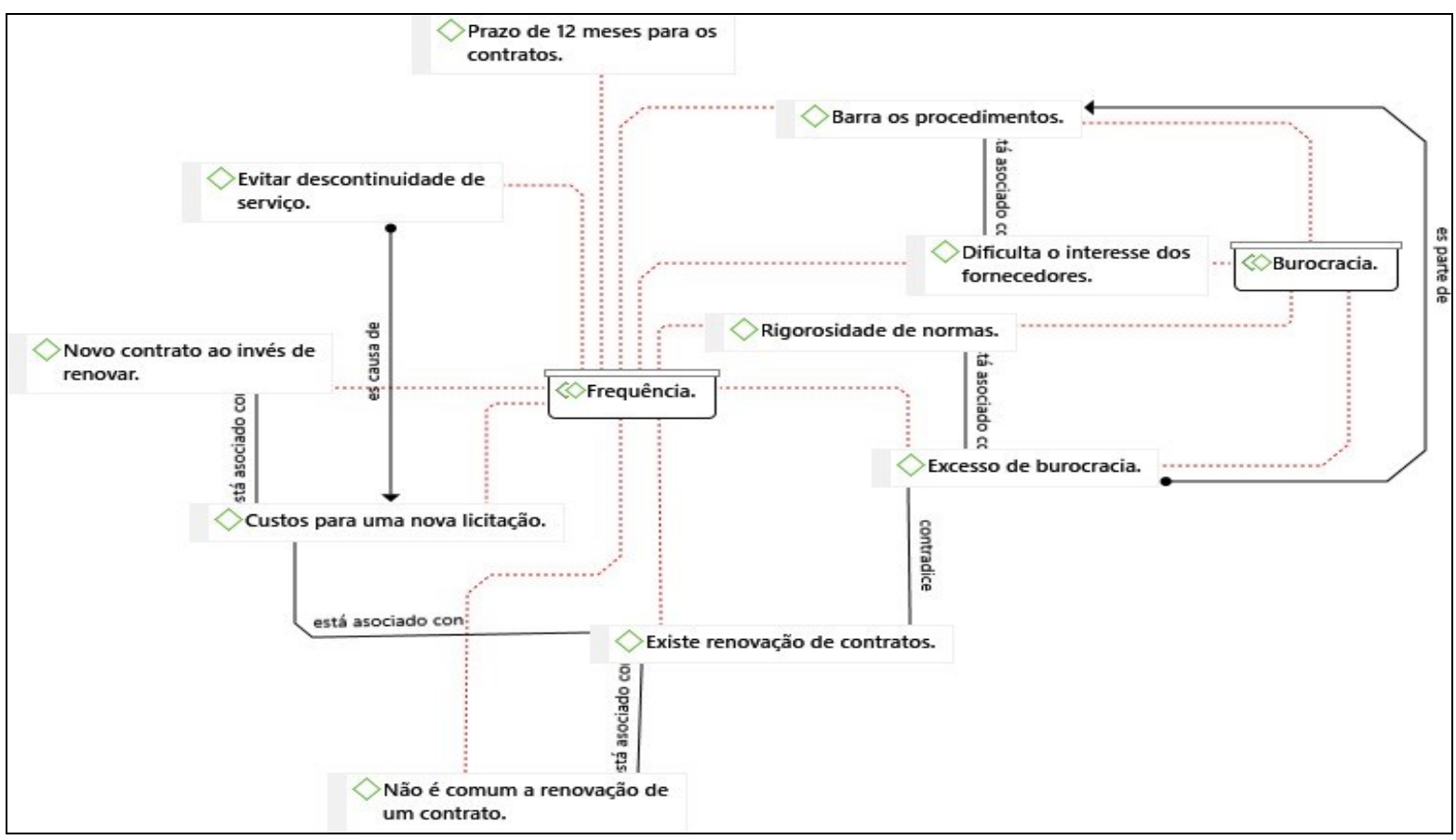

Fonte: elaborada pelos autores (2018).

\section{CONSIDERAÇÕES FINAIS}

Este estudo tem como objetivo identificar o efeito da burocracia no custo de transação econômica na Pró-Reitoria de Administração da Universidade Federal Rural do Semi-Árido no Estado do Rio Grande do Norte. Nessa perspectiva, constatou-se, inicialmente, a presença da incerteza no que concerne aos aspectos políticos e econômicos. Percebe-se, portanto, que as incertezas presentes estão relacionadas com as condições de mercado, que podem alterar os preços do fornecedor.

Ao levar em conta que a frequência é um forte atributo para minimizar a racionalidade limitada, a incerteza e o oportunismo, observou-se, na pesquisa, que esta característica não existe, em razão do processo de compra ser realizado com base no menor preço, desconsiderando o conhecimento e uma possível parceria que poderia ser construída, ao longo do tempo, com o fornecedor.

Porém, com o decreto da instrução normativa $n^{\circ} 05$, que regulamenta a necessidade de um processo de planejamento completo antes da aquisição, percebe-se uma perda na intensidade da incerteza, no oportunismo e na racionalidade limitada na relação entre os agentes. A redução da intensidade da incerteza se dá pela estabilidade das organizações públicas, onde detém contratos padronizados, compostos de salvaguardas, que controlam os 


\section{EFEITO DA BUROCRACIA NO CUSTO DE TRANSAÇÃO ECONÔMICA NA PRÓ-REITORIA DE ADMINISTRAÇÃO DA UNIVERSIDADE FEDERAL RURAL DO SEMI-ÁRIDO \\ DOI: http://dx.doi.org/10.5007/1983-4535.2020v13n2p71}

custos de transação existentes. Em se tratando da diminuição de intensidade do oportunismo, foi visto que a aplicação de sanções, em razão de descumprimentos contratuais, causa receios aos fornecedores. E no tocante à racionalidade limitada, a sistematização do processo de compra reduz o seu efeito, uma vez que as informações utilizadas para o procedimento de aquisições são eficientes à execução das atividades na administração pública.

Sendo assim, os procedimentos burocráticos, existentes na instituição pública, onde exige que sejam cumpridas certas regras, normas e regulamentos, não reduzem o custo de transação em sua plenitude, porém atenua. Logo, conclui-se que uma estrutura burocrática, na administração pública, é fundamental para adequar os interesses contratados entre os agentes.

A limitação, desta pesquisa, deu-se em razão da dificuldade para aplicar a entrevista com os diversos setores existentes na PROAD, tendo em vista que o período de realização compatibilizou com as férias dos responsáveis de cada divisão. Para pesquisas futuras, sugere-se que busquem, em outras instituições federais de ensino superior, respostas para essa mesma problemática, com enfoque no setor de compras, a fim de corroborar ou refutar com o resultado encontrado, bem como poderia ampliar esta pesquisa para outras PróReitorias da Universidade Federal Rural do Semi-Árido do Estado do Rio Grande do Norte.

\section{REFERÊNCIAS}

ARAGÃO, C. V. Burocracia, eficiência e modelos de gestão pública: um ensaio. Revista de Serviço Público, Brasília, v. 48, n.3, p. 104-132, Set/Dez. 1997.

BAIRRAL, M. A. C.; SILVA, A. H. C.; ALVES, F. J. S. Transparência no setor público: Uma análise dos relatórios de gestão anuais de entidades públicas federais no ano de 2010.

Revista de Administração Pública, v. 49, n. 3, p. 642-675, maio/jun. 2015.

BRASIL. Lei n. ${ }^{\circ}$ 8.666, de 21 de junho de 1993. Regulamenta o art. 37, inciso XXI, da Constituição Federal, institui normas para licitações e contratos da Administração Pública e dá outras providências. Diário Oficial da União. Brasília, DF, 1993. Disponível em: http://www.planalto.gov.br/ccivil_03/leis/18666cons.htm . Acesso em: 23 fev. 2018.

CARIO, S. A. F.; NEUENFELD, D. R.; STADNICK, K. T. Custos de Transação nas compras públicas - um estudo de caso na empresa de correios e telégrafos - SC. I CIDESP, Santa Catarina, Set. 2017. Disponível em: cidesp.com.br/index.php/Icidesp/1cidesp/paper/download/127/107 . Acesso em: 21 fev. 2018.

CARVALHO JÚNIOR, L. C; OZON, R. T. Análise das Transações e das Estruturas de Governança na Cadeia do Feijão da Região de União da Vitória/Pr. In: Congresso da Sociedade Brasileira de Economia, Administração e Sociologia Rural, XLII, 2004, Cuiabá. 


\section{EFEITO DA BUROCRACIA NO CUSTO DE TRANSAÇÃO ECONÔMICA NA PRÓ-REITORIA DE ADMINISTRAÇÃO DA UNIVERSIDADE FEDERAL RURAL DO SEMI-ÁRIDO \\ DOI: http://dx.doi.org/10.5007/1983-4535.2020v13n2p71}

Anais eletrônicos. Disponível em: http://www.sober.org.br/palestra/12/04O212.pdf . Acesso em: 17 jan. 2018.

CAMPOS, S. A. P. A economia dos custos de transação e a visão baseada em recursos: aproximações teóricas. Revista Reuna, Belo Horizonte, v. 18, n. 3, p. 5-20, setembro. 2013.

COASE, R. H. The nature of the firm. Economica, New Series, v. 4, n. 16, p. 386-405, novembro, 1937.

COSENZA, J. P.; TEIXEIRA FILHO, A. C.; LOPES, R. S. S. R. Reflexão sobre relações entre poder e contabilidade. Contabilidade, Gestão e Governança, Brasília, v. 15, n. 2, p. 75-94, mai/ago 2012.

DORNELES, T. M.; BINOTTO, E.; HOLGADO-SILVA, H. C.; RODRIGUES, W. O. P. Análise dos atributos das transações e estruturas de governança do setor apícola de Mato Grosso do Sul. Revista Brasileira de Gestão e Desenvolvimento Regional, São Paulo, v. 10, n.2, p. 3-23, 2014.

FARIA, J. H.; MENEGHETTI, F. K. Burocracia como organização, pode e controle. Revista de Administração de Empresas, São Paulo, v. 51, n. 5, p. 424-439, set/ out 2011.

GIRGLIOLI. P. P. Burocracia. Burocracia. In: BOBBIO, N.; MATTEUCCI, N.; PASQUINO, G., Dicionário de Política, 7. ed., Brasília-DF: Editora UnB, p. 124-130, 1995.

GRIN, E. J. Trajetória e avaliação dos programas federais brasileiros voltados a promover a eficiência administrativa e fiscal dos municípios. Revista de Administração Pública, Rio de Janeiro, v. 48, n. 2, p. 459-480, 2014.

KLEIN, K.; PIZZIO, A.; RODRIGUES, W. Governança universitária e custos de transação nas universidades da Amazônia Legal Brasileira. Educação e Sociedade, Tocantins, v. 39, n. 143, p. 455-474, fev. 2018.

LOPES, A. E. M. P. Dependência de recursos e custos de transação: rumo a um modelo convergente. Gestão e Produção, São Paulo, v. 24, n. 4, p. 806-813, 2017.

LYRIO, M. V. L.; DELLAGNELO, E. H. L.; LUNKES, R. J. Proposta de um modelo de análise da flexibilização da burocracia em organizações públicas com base nas dimensões sugeridas por Volberda: o caso da Secretaria de Estado da Administração de Santa Catarina. Administração Pública e Gestão Social, Santa Catarina, v. 9, n. 4, p. 254-264, 2017.

MARChetTi, C. T. C.; CARVAlHO, R. T.; MONT’AlVÃO, C. A. A influência da gestão burocrática nas organizações públicas do Brasil. Revista INICIA, Minas Gerais,, v. 9, p. 8$17,2009$.

MARTINS, D. L. C. C.; SOUZA, J. P. Atributos da transação e mensuração, e sua influência nas relações entre cooperados e cooperativas em sistemas agroindustriais suinícolas. Revista de Administração Mackenzie, São Paulo, v. 15, n. 3, p. 69-100, Maio/Jun. 2014. 
MELlO, F. O. T.; PAULILLO, L. F. O. Análise do alinhamento entre os atributos das transações e as formas de governanças empregadas na citricultura. Gestão e Produção, v. 16, n. 4, p. 679-690, 2010.

MOTTA, F.C.P. Controle social nas organizações. Revista de Administração de Empresas, São Paulo, v.19, n.03, p.11-25, jul./set., 1979. Disponível em:

http://www.scielo.br/scielo.php?script=sci_arttext\&pid=S0034-75901979000300002. Acesso em: 03 ago. 2017.

OLIVEIRA, I. G. S.Análise de correspondência aplicada a preposições sobre a eficiência e eficácia do processo de compras públicas a partir da percepção de diferentes atores envolvidos. Revista Ciências Administrativas, v. 21, n. 1, p. 131-162, 2015.

OURA, M. M.; KONO, C. M.; RODRIGUES, L. C.; RICCIO, E. L. O Pregão Eletrônico como Instrumento de Controle de Oportunismos no Processo Licitatório Público. Gestão e projetos, São Paulo, v. 3, n. 2, p. 260-281, maio/ago 2012.

REIS, P. R. C.; CABRAL, S. Para além dos preços contratados: fatores determinantes da celeridade nas entregas de compras públicas eletrônicas. Revista Administração Pública, Rio de Janeiro, v.52, n. 1, p. 107-125, jan 2018.

ROSA, R. A.; FREGA, J. R. Intervenientes do Processo de Transferência Tecnológica em uma Universidade Pública. Revista de Administração Contemporânea, v. 21, n. 4, p. 435457, 2017.

SANTOS, A. M.; PEREIRA, M. F. Universidade e modificação organizacional - do modelo burocrático à organização intensiva de conhecimento. Revista Gestão Universitária na America Latina - GUAL, Florianópolis, v. 5, n. 1, p. 01-27, 2012.

SANTOS, L.; BRONNEMANN, M. R. Desafios da gestão em instituições de ensino superior: um estudo de caso a partir da percepção de diretores de centro de uma IES pública do sul do Brasil. Revista Gestão Universitária na América Latina - GUAL, Florianópolis, v. 6, n. 1, p. 01-21, jan 2013.

SANTOS, L. A. S.; MARQUES, D. B. Burocracia e Economia dos Custos de Transação: Uma análise da relação entre a Universidade Federal de Pernambuco e a Refinaria Abreu e Lima. Administração Pública e Gestão Social, Recife, v. 7, n. 1, p. 26-37, jan/mar 2015.

SANTOS, M. S.; PADULA, A. D. A transação como fator estruturante da cadeia de suprimento do biodiesel no Rio Grande do Sul. Revista Eletrônica de Ciência Administrativa, Paraná v. 11, n. 2, p. 178-192, jul/dez 2012.

SARTURI, C. A. Os modelos de Administração Pública: patrimonialista, burocrática e gerencial. Conteúdo jurídico, Brasília, maio. 2013. Disponível em:

http://www.conteudojuridico.com.br/?artigos\&ver=2.43523\&seo=1. Acesso em: 04 ago. 2017 
SILVA, A. A.; BRITO, E. P. Incerteza, Racionalidade Limitada e Comportamento Oportunista: Um estudo na Indústria Brasileira. Revista de Administração Mackenzie, São Paulo, v. 14, n. 1, p. 177-201, 2013.

TRAGTENBERG, M. Administração, poder e ideologia. São Paulo: Cortez, 1989.

WEBER, M. Ensaios de Sociologia. Rio de Janeiro: Guanabara Koogan, 1982.

WILLIAMSON, O. E. Transaction-cost economics: The governance of contractual relations, Journal of Law and Economics,v.22, p. 3-61,oct. 1979.

WILLIAMSON, O. E. The economic institutions of capitalism. New York: Free Press, 1985. 